\title{
DELIBERATIVE DEMOCRACY AND THE EPISTEMOLOGY OF DISAGREEMENT
}

\begin{abstract}
Our goal in this article is to explore the relevance of the recent debate on epistemology of disagreement for democratic theory and especially for deliberative democracy. When talking about democratic decision making, deliberative democrats typically stress the importance of consensus or at least some kind of higher-level agreement. According to one prominent view in the epistemology of disagreement debate, that might be called the view of conformists, in the case of peer disagreement we should revise our own beliefs or degrees of belief so that we end up in agreement with our epistemic peers. It is not surprising that deliberative democrats welcomed this result. In this paper I shall argue that deliberative democrats should not embrace too readily the view of conformists.
\end{abstract}

Keywords: deliberative democracy, epistemic peers, disagreement, the equal weight view

One of the central assumptions of deliberative democratic theory is that preferences and beliefs can be changed in the course of a public deliberation. The problem is that not any change in preferences and beliefs can be considered justified. The current debate within deliberative democratic theory therefore largely focuses on the issue whether a change of beliefs can occur in the course of a public deliberation which would result in bringing truth-tracking collective decisions (Estlund 2008). Even though early deliberative democratic theory has been primarily focused on the change of preferences, the center of attention of current debates are epistemic aspects of public deliberation. In this article, we will be primarily interested in the epistemic aspect of public deliberation that concerns the change of beliefs or the degrees of belief. An equally important proposition of the theory of deliberative democracy is that a change of preferences and beliefs should lead to a greater degree of agreement among participants in a public debate and ideally to consensus. However, in political arena with participants which differ along numerous dimensions, disagreement is more

1 Earlier version of this paper was presented at the Democracy and Truth conference organized by the Department of Philosophy, Faculty of Philosophy, University of Belgrade, October 5-6, 2013. I am grateful to participants of the conference for very helpful discussions. This paper was realized as a part of the projects No. 43007 and No. 41004 financed by the Ministry of Education, Science and Technological Development of the Republic of Serbia. 
likely than reaching of a consensus. Our paper will thus attempt to consider whether it is rational for a participant to change one's beliefs or degrees of belief in circumstances of disagreement. Given that it is the central issue of the current debate on epistemology of disagreement, we will pay special attention to this debate. Our aim is to explore whether debate on epistemology of disagreement can help solve difficulties in reaching consensus in the political arena, a problem faced by contemporary theory of deliberative democracy.

Disagreement is a social fact. Democracy might not be uniquely the best way to solve the problems of disagreement, but it certainly is normatively, amongst the most appealing mechanisms. Let's say that I prefer policy A over policy B, and that two other persons Mark and Jane have exactly the opposite preference orderings. We cast our votes and policy B wins. Of course, I still think that this is not the right decision, that is to say I disagree with them over the outcome of the decision making process. Still, I prefer to solve our disagreement over policies $\mathrm{A}$ and $\mathrm{B}$ by casting votes over using violence or threats of violence. We may take majority voting procedures to be legitimate even when we disagree with their outcomes. Some people argued that there is something paradoxical about this conclusion (Wollheim 1962). I cannot, on pain of incoherence, endorse the procedure that produces the result that I disagree with.

Deliberative democrats think that if the democratic decision process includes not only voting, but also public deliberation, then this problem might be solved. They hope that talking prior to voting may influence some people to change their views for the right reasons. After hearing reasons for or against different proposals from other people we may reduce our disagreement over the correct outcome of the decision making process. If Mark and Jane have good reasons to support policy B, then I may be convinced by force of the better argument that I should also vote for policy B. In an ideal case of unanimous agreement, we don't need a voting procedure at all, but many political philosophers remain skeptical about the possibility of reaching consensus in the political arena (Bohman and Richardson 2009). The most to which we can realistically aspire would be some kind of meta-agreement (Dryzek and List 2003; Knight and Johnson 2011). Even if we disagree over our first-order preferences, we may still reach an agreement over the dimension of our disagreement. That is to say we may agree on what the common dimension of our disagreement is, and structure our first-order preferences accordingly. So, deliberative democrats hold that by means of public deliberation we may arrive at correct or at least at rational social choices. The democratic decision process aims toward consensus or at least some kind of meta-level agreement.

It seems that democratic decision making procedures which include talking prior to voting, have an epistemic advantage over the procedures that simply aggregate votes or opinions. In order to explain this advantage, Goodin highlighted the difference between mechanical information-pooling and discursive information-pooling. Actually, he defines deliberative democracy as ,information pooling by means of talk” (Goodin 2008, 94). Consider the following example that Goodin uses in order to motivate the difference between 
mechanical information-pooling and discursive information-pooling. You are a jury member in a case where a company is being sued for alleged extensive environmental damage. After hearing all the parties, the foreperson of the jury asks you to write down two things. Firstly whether or not the defendant is guilty, and secondly, if guilty, what would be the right amount of money as compensation of the damage done. You know that the plaintiff asks for compensation of \$2 million. Now you think that the defendant is guilty, but you are not sure about the amount of damages, because $\$ 2$ million is a lot of money. You decide therefore to be cautious. You think that $\$ 2$ million plus or minus half a million dollars is the right sum, and you are $95 \%$ confident that the right sum lies somewhere within that interval. It is time to write down your opinion. Firstly, you write down that you find the defendant guilty, but then you cautiously decide to write down the sum of $\$ 1.75$ million. After collecting judgments from all the jury members, a foreperson declares that they have reached a unanimous verdict, because all members of the jury have written down the same thing. Imagine a slightly different scenario in which, prior to declaring that the members of the jury have reached a unanimous agreement, they had a chance to talk about the reasons that support their judgment. During that process they may learn that they all were thinking that $\$ 2$ million is the right sum, but each and every member of the jury was also thinking that they should proceed cautiously. Upon learning about the reasoning process of the other members of the jury it may turn out that ,their prudent caution when forming a private judgment is overcome by confirmation from many other independent and equally reliable jurors" (Goodin 2008, 100-101).

If we take the first scenario as an instance of mechanical information-pooling, we may easily discover that in the second scenario some extra information is added that is crucial for reaching the right decision. Goodin claims that "the discursive process differs in allowing you to probe not only what the other person's probability assessment is but also why she thinks that to be so" (Goodin 2008, 95-96). And this is, according to Goodin, the main advantage of discursive opinion-pooling over mechanical opinion-pooling. Via the discursive opinionpooling process we learn not just the probability that other people assign to the claim that $P$ is true, we also learn whether or not our reporters are reliable. If we follow the mechanical opinion-pooling process we should revise our probability assessment that $P$ is true after hearing that some other people believe with much higher confidence that $P$ is true. As the number of reports that $P$ is true increases, my probability estimate should increase accordingly, but it is only by means of the discursive opinion-pooling that I could learn whether my informants are reliable enough. It may be that Mark and Jane's higher confidence that $P$ is true is due to the overconfidence effect, and after learning about their bias to assign higher probability to events not so probable, the conditional probability that the proposition ' $P$ is true, given that Mark and Jane say it is true', ought to fall. If we put things in terms of all or nothing belief, rather than probabilistic belief, then in these kinds of cases we should be completely unmoved by their belief that 'not $P$ ', when we believe that $P$ is true. 
It seems to me that a deliberative democrat faces the following dilemma. Call it the dilemma of a deliberative democrat. On the one hand, deliberative democrats claim that by means of public deliberation we may arrive at consensus or at least reach some kind of meta-agreement. In any case, public deliberation should reduce the scope of our disagreement. But on the other hand, in a process of public deliberation we may also learn about other people's biases, their weak arguments etc, which should make us more confident in holding our dissenting beliefs. Therefore, instead of leading to an agreement, a public deliberation may end up in some kind of belief polarization. A deliberative democrat cannot claim that both are at the same time desirable goals of public deliberation. It may be that deliberative democrats who rely on meta-agreement instead of consensus have an answer to the aforementioned dilemma. According to those theorists, if we reach an agreement on a meta-level, it doesn't matter whether disagreements over our first-order preferences remain or not. They also collected some evidence from deliberative polls to support this claim (List et al. 2006). I agree with their conclusions, but I also think that this answer is 'preferencist' in its nature. My main concern, however, is with the question, should our beliefs or degrees of belief change when facing disagreement. In what follows I shall explore whether the recent debate on the epistemology of disagreement might be of some help for resolving the dilemma of a deliberative democrat.

When we hear the opinion of an expert it might be reasonable for us to defer completely to their judgment, but what should we do in cases where only partial deference is warranted? That is to say, what should we do when our advisors are epistemic peers? When we say that someone is our epistemic peer it usually means that every piece of evidence that is available to us is also available to that other person and that we are roughly equal in our intellectual or reasoning abilities (so, if I am biased in a certain way, then the other people are also likely to be biased in the same way). I think that deliberative democrats should find this appealing because they try to make a lot out of the idea of equality. What therefore should we do when we disagree with someone who is our epistemic peer?

In the epistemology of disagreement literature, there are two main camps which offer opposing answers to this question. They may be called the view of conformists and the view of nonconformists (I borrow these labels from Lackey 2010). I will discuss only the main representatives of these views. According to the view of nonconformists in cases of peer disagreement, it might be reasonable for you to stick to your guns if you have good reasons to do so. Kelly, who is the main proponent of this view, maintains that „once I have thoroughly scrutinized the available evidence and arguments that bear on some question, the mere fact that an epistemic peer strongly disagrees with me about how that question should be answered does not itself tend to undermine the rationality of my continuing to believe as I do" (Kelly 2005, 170). However, if we assume there is perfect symmetry between epistemic peers, then there is no objective criterion that will make it more probable that I am more likely than my epistemic peer to be correct. As Kelly put it, there is no symmetry breaker. According to nonconformists the crucial question then is this: „why shouldn't 
I take this difference between us as a relevant difference, one which effectively breaks the otherwise perfect symmetry?" (Kelly 2005, 179). It is possible, then, from the point of view of nonconformists, that on some particular occasion one of the epistemic peers has worked harder in judging the evidence and draws the right conclusion, and this might be the symmetry breaker. This representative view that belongs to the family of nonconformist views is usually called the right reasons view.

Conformists, on the other hand hold, that if we do not have independent reason to downgrade the opinion of an epistemic peer, then we should revise our belief or degrees of belief toward that of an epistemic peer. They usually subscribe to the Uniqueness Thesis. Feldman says that „our options with respect to any proposition are believing, disbelieving, and suspending judgment. The Uniqueness Thesis says that, given a body of evidence, one of these attitudes is the rationally justified one" (Feldman 2007, 205). From the family of conformist views we will focus on the equal weight view which says that in cases of peer disagreement we should split the difference, that is, meet our epistemic peers halfway. Consider the following example (this example is a retelling of the „restaurant" case from Christensen 2007). Mark and Jane have just finished their dinner in a restaurant. They have eaten together in restaurants many a time, and they always split the cost evenly. After seeing the bill, they are both doing the math in their head and Mark says that their share is $\$ 43$ each, while Jane says that their share is $\$ 45$ each. Of course, they can check their arithmetic again. But, what if their disagreement remains? Christensen says that in cases like this „it seems quite clear that I should lower my confidence that my share is $\$ 43$, and raise my confidence that it's $\$ 45$. In fact, I think...that I should now accord these two hypotheses roughly equal credence" (Christensen 2007, 193).

When we set the stage for discussing the epistemology of disagreement, we should note that both views face serious objections. Lackey (2010), who defends the middle position called the justificationist view, presents these objections in forms of many against one and one against many. Let's say that Mark just went to the Saloma restaurant. He and Jane have a long history of eating dinner in that restaurant. He meets Jane and says that he is going to Jalan Ampang Street to have dinner in the Saloma restaurant. Jane then says that the Saloma restaurant is not in Jalan Ampang Street, but in Jalam Perak Street. Since they've been there many times together Mark might suspect that something is wrong with Jane's claim, because he is quite sure that the restaurant is in Jalan Ampang Street. What if they then meet five other people, who say that the restaurant is in Jalam Perak Street. Would it be still rational for Mark to have the same degree of confidence if say a hundred people hold that the restaurant is in Jalam Perak Street. It now seems counter-intuitive to think that it is reasonable for you to stick to your guns when many people disagree with you. This is the many against one objection that targets the view of nonconformists. The view of conformists, however, faces an objection that might be called the one against many objection. Let's say that in the previous example with the restaurant bill there are many other people, say a hundred of them, who say that the right sum is $\$ 43$. According to the 
view of conformists, despite an agreement with many other people, we should withhold our belief when we face just one instance of disagreement. This seems counter-intuitive, too. I will not go any further in answering these objections. In what follows I want to focus on the equal weight view. My main concern is with the question of whether or not the proponents of deliberation may rely on the equal weight view in order to resolve the dilemma of a deliberative democrat. The reason for this is that some democratic theorists argued recently that the equal weight view is of the utmost importance for understanding the epistemic dimension of public deliberation (Peter 2013).

It seems reasonable for a deliberative democrat to adopt the following strategy. Assume that in a deliberative setting, disagreements are to be expected, and that people should be treated as epistemic peers. By applying the equal weight view we may expect that disagreements will dissolve, so by means of the equal weight view we solve the dilemma of a deliberative democrat. This suggests that reasonable disagreement is not possible and that in cases of peer disagreement we should move toward consensus. Fabienne Peter clearly endorses this line of reasoning when she says that „what has come to be called the Equal Weight View... claim that reasonable disagreements are not possible. On this view, absent any further information, the rational response to a disagreement between peers is for each to meet the other halfway and thus to dissolve the original disagreement. As long as Uniqueness holds and each has access to the same body of evidence, two peers who are were likely to perform well cannot both be justified to hold the original beliefs they do and so a reasonable disagreement between them is not possible. On this view, rational deliberation between peers forces them to reach an agreement" (Peter 2013, 1257). But how successful is this strategy? In order to see that, we now turn to the equal weight view.

Elga provides the following argument in favour of the equal weight view (Elga 2007, 486-487). Suppose for the sake of argument that it is reasonable for Mark to be $70 \%$ confident that he is correct in judging a horse race between, say, horse $\mathrm{N}$ and horse $\mathrm{M}$, and let's say that he is confident that horse $\mathrm{N}$ won the race. Now his friend Jane who is as good as Mark in judging horse races is confident that horse $\mathrm{M}$ won. Since Mark is $70 \%$ confident that he is right, merely by noticing disagreement with Jane he got the evidence that he is a better judge of horse races. Since it is absurd to think that someone is a better judge only because of noticing disagreements with other people without any independent reason to think so, the starting assumption cannot be correct. This becomes even more evident if we take, that instead of one race, there are several races. If Mark is $70 \%$ confident that he is right on each race, after many disagreements with Jane he will end up extremely confident that he is a better judge of horse races. Again, it seems absurd to think that someone is a better judge simply because of disagreements with other people and without any independent reason to think so. Elga points out that in cases of peer disagreement we should think that other people are equally likely to be correct (Elga 2007, 487). Assuming otherwise would lead to absurdity.

Where does this all leave us? Since, „according to the equal weight view, one should give the same weight to one's assessment as one gives to the assessment 
of those one counts as one's epistemic peers" (Elga 2007, 484), it seems that it is possible after all to reach consensus in the circumstances of disagreement. Is it reasonable then, for a deliberative democrat to rely on the equal weight view? Here is why the answer is "no". Elga makes further distinction between pure and messy real-world cases of disagreement (Elga 2007, 492). The equal weight view seems correct in the pure cases of peer disagreement, but in the messy realworld cases it seems absurd because it would recommend suspending judgment on almost every moral and political question. The problem is that in the pure cases of peer disagreement, counting someone as an epistemic peer is „based on reasoning that is independent of the disputed issue" (Elga 2007, 492). That, however, is not the case in the messy real-world disagreements. Here, reasoning about the disputed issue is interconnected with many other issues, and there might be a lot of disagreements about these other issues, too. If we think that someone got it wrong on many of these issues, then we will not think that they will get it right on the disputed issue. The upshot is that in the messy real-world cases we don't treat each other as epistemic peers. The critical contrast is this:

Think of a smart and well-informed friend who has a basic political framework diametrically opposed to your own. Imagine that the two of you are both presented with an unfamiliar and tricky political claim. You haven't thought things through yet, and so have no idea what you will eventually decide about the claim. Still-don't you think that you are more likely than your friend to correctly judge the claim, supposing that the two of you end up disagreeing? If so, then however quick-witted, well-informed, intellectually honest, and thorough you think your friend is, you do not count her as an epistemic peer with respect to that claim. And if you do not count her as a peer, the equal weight view does not require you give her conclusion the same weight as your own. Indeed, if you think that your friend has been consistently enough mistaken about allied issues, then the equal weight view requires you to become more confident in your initial conclusion once you find out that she disagrees.

At the other extreme, think of a smart friend who has a basic political framework extremely similar to your own. Again, imagine that both of you have just been presented with an unfamiliar political claim. In this case, you may well think that in case of disagreement, your friend is just as likely as you to be correct. If so, and if you and your friend end up coming to opposite verdicts, then the equal weight view requires you to think it just as likely that she is right as that you are. But notice that friends like these-friends who agree with you on issues closely linked to the one in question-will very often agree with you on the one in question as well. (Elga 2007, 493-494)

The preceding discussion suggests that deliberative democrats should not embrace too readily the equal weight view. Our central objection is that by using the equal weight view as a part of the strategy for resolving the dilemma of a deliberative democrat, one actually assumes what one claims to be proving. Deliberative democrats think that the common political framework should be forged through the process of public deliberation. The point here is that in order to apply the equal weight view they have to presuppose the common political framework. When this point is appreciated it becomes clear that a deliberative 
democrat cannot rely on the equal weight view in order to resolve the dilemma. Hence the argument based on the equal weight view does not go through.

In this article we have claimed that an important problem faced by deliberative democratic theory is that public deliberation may lead to reaching of a consensus, but also to a reasonable disagreement. A deliberative democrat cannot claim that both are at the same time desirable goals of public deliberation. We have called this problem the dilemma of a deliberative democrat. The gist of our article was consideration whether contemporary debate on epistemology of disagreement can help solve this problem. In that sense, we have particularly considered the position called the equal weight view which states that in a situation of a disagreement among epistemic peers, the only rational answer is meeting halfway, which simultaneously leads to reaching of a consensus. However, we have concluded that the equal weight view provides only limited support to the theory of deliberative democracy and that the dilemma of a deliberative democrat cannot be resolved on its premises.

\section{References}

Bohman, James and Henry S. Richardson (2009) „Liberalism, Deliberative Democracy, and 'Reasons that All Can Accept"', The Journal of Political Philosophy 17: 253-274.

Christensen, David (2007) „Epistemology of Disagreement: The Good News,” Philosophical Review 116: 187-217.

Dryzek John S. and Christian List (2003) „Social Choice Theory and Deliberative Democracy: A Reconciliation," British Journal of Political Science 33: 1-28.

Elga, Adam (2007) „Reflection and Disagreement,” Noûs 41: 478-502.

Estlund, David M. (2008) Democratic Authority: A Philosophical Framework, Princeton and Oxford: Princeton University Press.

Feldman, Richard (2007) „Reasonable Religious Disagreements, in Antony L. (ed.), Philosophers without Gods: Meditations on Atheism and the Secular Life, Oxford: Oxford University Press, pp. 194-214.

Goodin, Robert E. (2008) Innovating Democracy: Democratic Theory and Practice After the Deliberative Turn, Oxford: Oxford University Press.

Kelly, Thomas (2005) „The Epistemic Significance of Disagreement," in Gendler T. S. and J. Hawthorne (eds.), Oxford Studies in Epistemology, Volume 1, Oxford: Oxford University Press, pp. 167-196.

Knight, Jack and James Johnson (2011) The Priority of Democracy: Political Consequences of Pragmatism, Princeton: Princeton University Press.

Lackey, Jennifer (2010) „A Justificationist View of Disagreement's Epistemic Significance," in Haddock A., Millar A., and D. Pritchard (eds.), Social Epistemology. Oxford: Oxford University Press, pp. 298-325.

List, Christian, Luskin, Robert C., Fishkin, James S., and Iain McLean (2006) „Deliberation, Single-Peakedness, and the Possibility of Meaningful 
Democracy: Evidence from Deliberative Polls," PSPE working papers, 012006. Department of Government, London School of Economics and Political Science, London, UK.

Peter, Fabienne (2013) „The Procedural Epistemic Value of Deliberation,” Synthese 190:1253-1266.

Wollheim, Richard (1962) „A Paradox in the Theory of Democracy”, in Laslett P. and W. G. Runciman (eds.) Philosophy, Politics and Society, Oxford: Blackwell, pp. 71-87. 